\title{
Acute anterior uveitis, ankylosing spondylitis, back pain, and HLA-B27
}

\author{
ADRIAN B. BECKINGSALE, JONATHAN DAVIES, JONATHAN M. GIBSON, \\ AND A. RALPH ROSENTHAL
}

From the Department of Ophthalmology, University of Leicester School of Medicine, Leicester

SUMmARY One hundred and sixty-nine patients with acute anterior uveitis were studied for the presence of HLA-B27 tissue type, radiological evidence of ankylosing spondylitis, and a history of back pain. $60 \%$ were male; $45 \%$ were HLA-B27+. The male:female ratio in the HLA-B27+ group was the same as in the whole group. $24 \%$ had radiological evidence of ankylosing spondylitis, and, of these, $83 \%$ were HLA-B27+ while $17 \%$ were HLA-B27-. There was a definite correlation between the severity of the ankylosing spondylitis and preponderance of males in the HLA-B27+ group of patients. Significant back pain occurred in $60 \%$ of HLA-B27+ patients but in only $14 \%$ of HLA-B27- patients. The importance of the selection of patients and of consistency in the use of diagnostic criteria in studies relating to ankylosing spondylitis and acute anterior uveitis is stressed.

Since the association between the presence of HLAB27+ tissue type, ankylosing spondylitis (AS), ' and acute anterior uveitis (AAU) ${ }^{2}$ was first described in 1973 a deluge of reports of other HLA associations and nearly all other diseases has appeared. $\mathrm{Rahi}^{3}$ reviews the various ocular associations and the possible mechanisms by which they may come about. In this study we attempt to quantify more ac....iately the HLA-B27 associations with AAU, AS. and back pain by employing a large number of randomly selected patients with AAU as well as using radiographic confirmation of AS.

\section{Patients and methods}

All patients presenting to the Casualty Unit of the Eye Clinic at the Leicester Royal Infirmary with AAU over a period of one year were included in this study. Two hundred and four patients with AAU were seen. Of these, $169(83 \%)$ had a questionnaire about back pain administered, their HLA-B27 status ascertained, and radiographic evaluation of their sacroiliac joints and lumbosacral spine.

All patients were questioned as to whether they suffered at the present time or in the past from back

Correspondence to Mr A. B. Beckingsale, Department of Ophthalmology, Clinical Sciences Building, Leicester Royal Infirmary, Lcicester. pain or stiffness. Patients with such symptoms were then further questioned by the screening questions for AS suggested by Calin and Fries. ${ }^{4}$ From their responses to these questions a decision was made as to whether the symptoms were suggestive of AS or not. The HLA-B27 status and the radiological findings of the patients were unknown to the questioner at the time of assessment.

The HLA-B27 status of the patients was tested by the tissue typing service of the British National Blood Transfusion Service, Sheffield.

A radiological diagnosis of AS was dependent on the demonstration of sacroiliitis and certain changes in the lumbar spine. The presence of sacroilliitis was ascertained by a system based on the New York criteria for the diagnosis of AS. ${ }^{5}$ The grading was as follows: grade 0 , normal; grade 1 , equivocal changes; grade 2, minor but definite changes, including small localised areas of sclerosis or erosion; grade 3, definite sclerosis, erosions, widened joint space, or partial ankylosis; grade 4, total ankylosis. Patients with bilateral sacroiliitis of grade 2 or more were considered to show definite evidence of AS.

The presence of the following radiological features recorded in the lumbar spine permitted confirmation of the diagnosis of AS: squaring of vertebral bodies, syndesmophytes, calcification of the anterior longitudinal ligament, and total spinal fusion (bamboo spine). 
HLA-B27 TISSUE TYPE

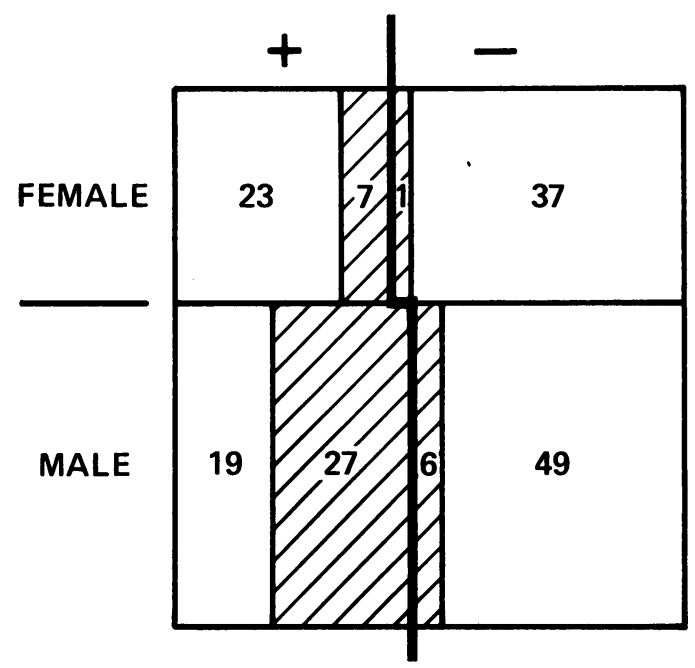

TOTAL GROUP: $n=169$

RADIOLOGIC EVIDENCE OF AS: $\mathbf{n}=\mathbf{4 1}$

Fig. 1 Group of 169 patients with AAU split according to sex, $H L A-B 27$ tissue type, and radiographic evidence of $A S$.

\section{Results}

Radiographs of the sacroiliac joints and lumbar spine of 169 patients whose HLA-B27 status was known and were suffering from AAU were available for study. One hundred and one $(60 \%)$ were males, 68 $(40 \%)$ were females. Seventy-six $(45 \%)$ were HLA$\mathrm{B} 27+$, and, of these, $46(61 \%)$ were male and 30 $(39 \%)$ were female. Of the remaining 93 HLA-B27patients $55(59 \%)$ were male and $38(41 \%)$ were female.

Radiological evidence of AS was found in 41 (24\%) of the 169 patients. Of these $41,34(83 \%)$ were HLA-B27+ and $7(17 \%)$ HLA-B27-. Of the 34 HLA-B27+ patients 27 were males and 7 females. Of the HLA-B27 negative individuals six were male. A single female patient with HLA-B27- tissue type had radiological changes of AS. Of the 128 patients without evidence of AS 42 (33\%) were HLA-B27+ and $86(67 \%)$ HLA-B27-. Of the 42 HLA-B27+ patients without evidence of AS $19(45 \%)$ were male and $23(55 \%)$ were female. Of the 86 HLA-B27patients without AS $49(57 \%)$ were male and 37 $(43 \%)$ were female. When they were subdivided by tissue type we found that 34 of $76(45 \%)$ HLA-B27+ patients and 7 of $93(8 \%)$ HLA-B27- patients had radiological evidence of AS. These associations are summarised in Fig. 1.

Back pain and symptoms suggestive of AS were found in $46 / 76(60 \cdot 5 \%)$ HLA-B27 + patients, 34 males
HLA-B27 TISSUE TYPE

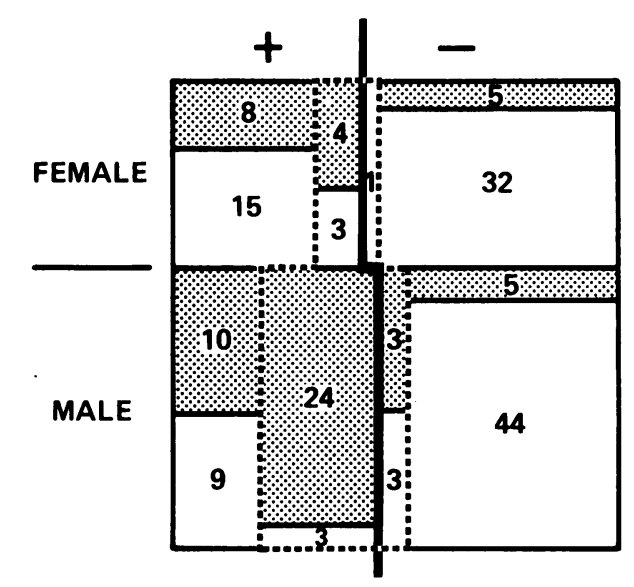

TOTAL GROUP: $n=169$

BACK PAIN: $n=59$

:.:: SUBGROUPS OF PATIENTS WITH RADIOLOGIC EVIDENCE OF AS: $n=41$

Fig. 2 Distribution of back pain among subgroups (as in Fig. 1) of AAU patients.

and 12 females, and in 13/93 (14\%) HLA-B27patients, eight males and five females. Ten $(53 \%)$ out of the 19 HLA-B27+ males and eight $(35 \%)$ out of the 23 HLA-B27+ females without radiological evidence had such symptoms, but only five $(10 \%)$ out of 49 HLA-B27- males and five (13.5\%) out of 37 HLA-B27- females without radiological evidence of AS had such symptoms. Of the 41 patients with radiological evidence of AS 10 had no symptoms, four were female (three HLA-B27 + and one HLA-B27-) and six were male (three HLA-B27+ and three HLA-B27-). These associations are summarised in Fig. 2.

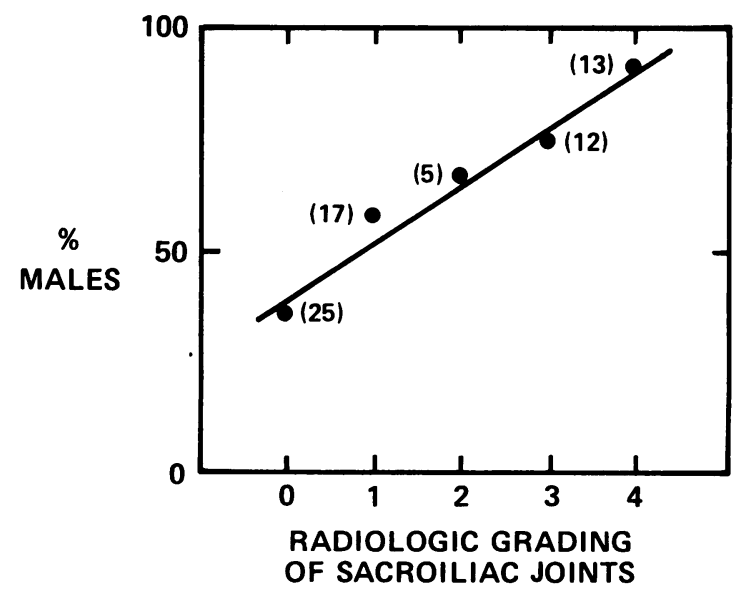

Fig. 3 Radiological grading of sacroiliac joints in patients with $A A U$ and the HLA-B27 tissue type with respect to sex. 
Table 1 Radiological findings in the lumbar spines of patients with sacroiliitis

\begin{tabular}{lc}
\hline Abnormality & $\begin{array}{l}\text { No. of } \\
\text { patients (\%) }\end{array}$ \\
\hline Normal & $6(15)$ \\
Squared vertebral bodies alonc & $9(22)$ \\
Syndesmophytes without spinal fusion & $8(19 \cdot 5)$ \\
Calcification of the anterior longitudinal ligament & $10(24)$ \\
Total spinal fusion (bamboo spine) & $8(19 \cdot 5)$ \\
Total & 41 \\
\hline
\end{tabular}

In both the total group and the HLA-B27+ group of patients as the severity of the grade of radiological change increased so did the preponderance of males $(r=0.98 ; p<0.01)$. These findings are summarised in Fig. 3.

The radiological findings in the lumbar spines of the 41 patients with sacroiliitis are shown in Table 1.

\section{Discussion}

\section{RELATIONSHIP BETWEEN AAU AND AS}

Between 20 and $30 \%$ of patients suffering from AS are found to suffer also from attacks of AAU. ${ }^{167}$ The converse relationship - the number of patients with AAU who are found to have AS as well-has also been studied. A surprisingly wide range of values, however, has been found, varying between 3.5 and $34 \%$. $^{8-10}$ Several factors may account for these widely differing values. A number of earlier series did not include routine radiography of the sacroiliac joints, nor did they specify the manner in which patients were investigated for rheumatic diseases. In addition the criteria for the diagnosis of AS were standardised only in 1963 and were revised it a conference in New York in $1968^{5}$ to the form in use today.

In some studies of AAU evidence of AS was actively sought. Lenoch et al." examined 474 patients with uveitis and found $17 \cdot 4 \%$ with AS. In series examined by routine radiography of the sacroiliac joints Brewerton et al. ${ }^{2}$ found $16 \%$ and Saari et al. ${ }^{9}$ found $34 \%$ of their patients with AAU to have AS as well. The finding from the present report, in which radiographic confirmation was used, of $24.3 \%$ lies in the middle of this range.

\section{SEX RATIO IN AAU AND AS}

In a population of patients with AS approximately $10 \%$ of the patients are female. ${ }^{12}$ The incidence of AS in AAU when correlated with sex shows considerable variation between different reported series. Lenoch et al. ${ }^{11}$ found $30 \cdot 8 \%$ of their male patients and only $3.9 \%$ of their female patients with AAU to have AS as well, whereas Brewerton et al. ${ }^{2}$ found less difference between sexes, with $17 \cdot 6 \%$ of men and $12.5 \%$ of women having AS. Saari et al. ${ }^{9}$ however, produced markedly contrasting results: $43 \%$ of the women and only $28 \%$ of the men had AS when 103 consecutive routinely $x$-rayed patients with AAU were considered. The present findings of $33 \%$ of men and $12 \%$ of women having documented AS are again intermediate between the first two series ${ }^{211}$ and at variance with the latter series. ${ }^{9}$ Furthermore, the present study showed that most of the women with sacroiliitis had the less severe grades of radiological change than the men, of whom more had grade 4 sacroiliitis than either grade 3 or grade 2 . Further, the ratio of men to women increases with increasing severity of the grade of sacroiliitis (Fig. 3). It is generally accepted that AS has a more benign course in women, ${ }^{13}$ and this study confirms this even in the presence of AAU.

\section{RADIOLOGICAL CRITERIA FOR THE DIAGNOSIS} OF AS

The assessment and comparison of studies of AS is difficult, as the exact criteria for diagnosis, either clinically or by radiographic means, are not always stated. We chose to include grades 2,3 , and 4 of radiographic sacroiliitis as defined by the New York criteria. ${ }^{5}$ Brewerton et al. ${ }^{1}$ felt that AS could be diagnosed radiographically only if changes of grade 3 or 4 were seen. However, in our series, of the 11 patients who had grade 2 radiographic sacroiliitis, six had lumbar spine changes suggestive of AS. Furthermore, the ratio of HLA-B27 + patients to HLA-B27patients with grade 2 sacroiliitis (i.e., $82 \%+$ to $18 \%-)$ is markedly different from the overall ratio of HLA-B27 tissue type (i.e., $45 \%+$ to $55 \%-$ ). Since the presence of the HLA-B27 tissue type has been linked so securely with AS, we feel that it is more realistic to consider bilateral grade 2 sacroiliitis as definite evidence of genuine AS.

HLA-B27 TISSUE TYPE IN AAU AND AS

In the present group of AAU patients $45 \%$ were HLA-B27+ and 55\% were HLA-B27-. This value compares favourably with that of Brewerton et al., who give a value of $43 \%$ HLA-B27+ in AAU. ${ }^{214} 15$ Others $^{16}{ }^{17}$ have shown nearer $60 \%$ of their uveitis patients to have HLA-B27+ tissue type.

Of our HLA-B27+ patients $45 \%$ had radiological evidence of AS, but in the HLA-B27- group only $7.5 \%$ had such radiological changes. These HLAB27 - patients, however, represent $17 \%$ of the total AS in the AAU patients. Scharf and Zonis ${ }^{18}$ state that HLA-B27+ tissue type is present in $98 \%$ of all patients with both AAU and AS together. Similarly other investigators state that all the patients with AAU and AS were HLA-B27+.${ }^{919}$ This has not been 
borne out in this series, where only $83 \%$ were HLA$\mathrm{B} 27+$. The discrepancy is probably due to the fact that Scharf and Zonis ${ }^{18}$ looked at series where AAU was sought in patients who were already known to have AS, and of course these patients would already be expected to have an incidence of HLA-B27+ of $90-95 \% .{ }^{4}$ In addition in the other series either small numbers of patients were studied ${ }^{20}$ or relatively few of the patients were tissue typed. ${ }^{9}$ The present series was of large numbers and closer to random sampling and may reflect a more accurate figure. We suggest, therefore, that HLA-B27-AAU with concomitant AS is commoner than previously thought and that this can be demonstrated if diligently sought in an unselected series of AAU patients. Furthermore the male to female ratio in the HLA-B27- patients with AS (6/1) was higher than those with the B27 tissue type $(27 / 7)$.

BACK PAIN AND AAU

Back pain and symptoms suggestive of AS were found in $60 \%$ of HLA-B27+ patients but in only $14 \%$ of HLA-B27- patients. In those without any radiological evidence of AS 10 (53\%) out of 19 HLAB27 + male patients and eight (35\%) out of 23 HLA-B27+ female patients had significant back pain and symptoms as compared with five $(10 \%)$ out of 49 HLA-B27- males and five (13\%) out of 37 HLAB27- females. It is clear, therefore, that in our study 'back trouble' is much more prevalent in HLA-B27+ AAU patients than HLA-B27- AAU patients even in the absence of radiological changes, and that this susceptibility is more marked in the male patients. It would be interesting to know if these purely symptomatic patients will later develop radiological changes and frank clinical evidence of AS. Calin and Fries ${ }^{21}$ found an increase in back symptoms in otherwise healthy HLA-B27+ subjects of both sexes of three times over HLA-B27 - subjects. Our findings were of a 10-fold increase of susceptibility in the HLA-B27+ men with AAU and of the same three-fold increase in HLA-B27+ women with AAU. These results are in conflict with those of Moller et al. ${ }^{20}$ who found no difference in incidence of back pain between HLAB27+ and HLA-B27- AAU patients. The relationship of AS and AAU is further confused by the observation that $63 \%$ of patients with AAU and radiographically normal sacroiliac joints have abnormalities of the sacroiliac joints consistent with early or modified AS on ${ }^{9 \%}$ technetium stannous pyrophosphate bone scans. ${ }^{19}$

PATIENT AWARENESS OF AS AND ITS SYMPTOMS No female in this series knew that she had 'ankylosing spondylitis,' which underlines the much greater reluctance of clinicians to entertain a diagnosis of AS in women than in men. This supports the findings of Hill et al. ${ }^{22}$ of a delay of 10 years in the diagnosis of AS in women as opposed to three years in men. Only 15 out of 25 males $(60 \%)$ with grades 3 and 4 radiological sacroiliitis knew that they had 'ankylosing spondylitis.' Interestingly, two patients with grade 3 and two with grade 4 sacroiliitis denied any previous back pain or symptoms despite the marked radiological changes. Calin et al. ${ }^{23}$ have reported that asymptomatic AS is very rare, but Beckingsale et al. ${ }^{24}$ have reported an appreciable incidence of asymptomatic AS in AAU. On the other hand patients with psoriasis-associated AS are not uncommonly asymptomatic. ${ }^{2526}$ Our symptomless AS patients, however, do not fall into this category, for none of them had any evidence of psoriasis nor did any of the five patients with psoriasis and AAU have radiological changes of AS.

\section{CONCLUSIONS}

This report has confirmed the association of HLAB27+ with AAU and AS, but we have also shown a quite appreciable incidence of AS in HLA-B27AAU. We have demonstrated a significant increase of back symptoms in patients with HLA-B27+ AAU over those who were HLA-B27-. We suggest that the variation of these results from previous work and within previous studies is due to patient selection and inconsistency in the use of diagnostic criteria. We feel that grade 2 radiological bilateral sacroiliitis in AAU can be regarded as definite evidence of the presence of AS.

\section{References}

1 Brewerton DA, Caffrey M, Hart FD, James DCO, Nicholls A, Sturrock RD. Ankylosing spondylitis and HL-A27. Lancet 1973; i: 904-7.

2 Brewerton DA, Caffrey M, Nicholls A, Walters D, James DCO. Acute anterior uveitis and HL-A27. Lancet 1973; ii: 994-6.

3 Rahi AHS. HLA and eye disease. Br J Ophthalmol 1979; 63: 283-92.

4 Calin A, Fries JF. Ankylosing spondylitis: discussions in patient management. Garden City, NY: Medical Examination Publishing Co., 1978: 42-3.

5 Gofton JP. In: Bennet PH, Wood PHN, eds. Population studies of the rheumatic diseases. Excerpta Medica International Congress Series, No. 148. Amsterdam: Excerpta Medica, 1968: 314-456.

6 Scharf J, Nahir M, Scharf J, et al. Anterior uveitis in ankylosing spondylitis: a histocompatibility study. Ann Ophthalmol 1979; 11: $1061-2$

7 Spencer DG, Park WM, dick HM, Papazoglou SN, Buchanan WW. Radiological manifestations in 200) patients with ankylosing spondylitis: correlation with clinical features and HLA-B27. J Rheumatol 1969; 6: 305-15.

8 Kimura SJ, Hogan MJ, O'Connor GR, Epstein WV. Uveitis and joint discases. Arch Ophthalmol 1967; 77: 309-16.

9 Saari R, Lahti R, Saari KM, et al. Frequency of rheumatic discases in patients with acute anterior uveitis. Scand $J$ Rheumatol 1982; 11: 121-3.

10 Stanworth A, Sharp J. Uveitis and rheumatic diseases. Ann Rheum Dis 1956; 15: 140-50. 
11 Lenoch F, Kralik V, Bartos J. Rheumatic iritis and iridocyclitis. Ann Rheum Dis 1959; 18: 45-7.

12 Hart FD, MacLagan NF. Ankylosing spondylitis: a review of 184 cases. Ann Rheum Dis 1955; 14: 77-82.

13 Resnick D, Dwosh IL, Goergen TG, et al. Clinical and radiographic abnormalities in ankylosing spondylitis: a comparison of men and women. Radiology 1976; 119: 293-7.

14 Brewerton DA, Caffrey M, Nicholls A, Walters D, James DCO. Acute anterior uveitis and HLA 27. Lancet 1974; i: 464.

15 Brewerton DA. HLA 27 and acute anterior uveitis. Ann Rheum Dis 1975; 34 (suppl): 33-5.

16 Miettinen R. Incidence of uveitis in Northern Finland. Acta Ophthalmol (Kbh) 1977; 55: 252-60.

17 Saraux H, Hors J, Lebensson AA, Nou B. HLA histocompatibility system and ocular diseases. Ann Oculist (Paris) 1976; 209: 351-6.

18 Scharf Y, Zonis S. Histocompatibility antigens (HLA) and uveitis. Surv Ophthalmol 1980; 24: 220-8.

19 Russell AS, Lentle BC, Percy JS, Jackson FI. Scintigraphy of sacro-iliac joints in acutc anterior uveitis: a study of thirty patients. Ann Intern Med 1976; 85: 606-8.
20) Moller P, Vinje O, Olsen EG, HLA B27, sacro-iliitis and peripheral arthropathy in acute anterior uveitis. Scand $J$ Rheumatol 1980; 9: 234-6.

21 Calin A, Fries JF. Ankylosing spondylitis: discussions in patient management. Garden City, NY; Mcdical Examination Publishing Co., 1978: 22-5.

22 Hill HFH, Hill AGS, Bodmer JG. Clinical diagnosis of ankylosing spondylitis in women and relation to presence of HLA B27. Ann Rheum Dis 1976; 35: 267-70.

23 Calin A, Fries JF, Schurman D, Payne R. The close correlation between symptoms and disease expression in HLA B27 positive individuals. J Rheumatol 1977; 4: 277-81.

24 Beckingsale AB, Guss RB, Rosenthal AR. Acute anterior uveitis associated with HLA B27 positive tissuc type: a comparative study in two populations. Trans Ophthalmol Soc UK 1982; 102: $168-70$.

$25 \mathrm{Jacic} \mathrm{I}$. Radiological changes in the sacro-iliac joints and spine of patients with psoriatic arthritis and psoriasis. Ann Rheum Dis $1968 ; 27: 1-6$.

26 Molin L. Psoriasis. Acta Derm Venereol (Stockh) 1973; 53 (suppl 72): 7-125. 